\title{
Uses and Bioactivy of Myristica fragrans Houtt for Education Purposes
}

\author{
Marina Silalahi \\ Department of Biology Education, Universitas Kristen Indonesia, Jakarta, Indonesia \\ E-mail: marina_biouki@yahoo.com; marina.silalahi@uki.ac.id
}

\begin{abstract}
Myristica fargrans is a type of spices from the Myristicaceae family that has been used for thousands of years. Numteg is used as food and traditional medicine. Utilization of plants as traditional medicine is considered safer compared to synthetic drugs. The writing of this article aims to reveal the bioactivity of Numteg which is based on literature review on line and off line. In ethnobotany, numteg is used as a cholesterol, prodisiac, hepatoprotective drug. Numteg's bioactivity functions as an antimicrobial, aphrosidiac, anti-depressant, analgesic, anti-cancer, and anticolytic agent. The use of numteg as aprosidiak needs to be studied further so as to improve its function as a standardized or phytochemical herbal
\end{abstract}

Keywords: Myristica fragrans, aphrosidiac, anti-depressant

\section{INTRODUCTION}

Indonesia has long been known as a source of various types of spices such as nutmeg (Myristica fargrans) and cloves (Syzygium aromaticum). Nutmeg or Myristica fargrans (MF) is a spice originating from the Moluccas Islands and has been widely cultivated in various regions in Indonesia and other countries. Although originating from the Moluccas Islands, Shafiei et al (2012) states that MF has long been cultivated for spices on the island of Penang, Malaysia (Shafiei et al 2012). Jaiswal et al (2009) stated that MF spices in the form of seeds and nutmeg.

MF has a distinctive aroma so it is widely used for the aroma of various types of food as the main ingredient and additional ingredients. MF rind is processed into various foods while the seeds are used for medicine. In the health field MF is used to declare MF used for the treatment of various intestinal diseases, including colitis in traditional Korean medicine Kim et al (2013). The Unani Medical System in India has long used spices considered as a sexual refresher and the management of male sexual disorders (Tajuddin et al 2005). Shafiei et al (2012) state that MF meat, seeds, and mace can be used as new natural agents in oral care products (Shafiei et aal 2012). Moinuddin et al (2012) showed the bioactivity of MF as an anti-depressant by using aromatherapy so that it gives a relaxing effect.

The chemical constituents of MF have been investigated for hypolipidemic effects of hypocholesterolemia, antimicrobials, antidepres- sants, aphrodisiacs, improving memory, antioxidants and hepatoprotective properties (Jaiswal et al 2009). Utilization of plants as medicinal materials including MF associated with secondary metabolite compounds. Tallei and Kolondam (2015) states that MF secondary metabolites have high values because of their benefits to the health, food industry, and beauty (Tallei and Kolondam 2015). The use of MF as a drug is related to its bioactive compounds, especially its essential oils. This study aims to explain the relationship between MF utilization and its bioactive compounds.

\section{METHODS}

The writing of this article is based on a literarure study of Myristica fragrans and its bioactivity. Most of these studies are sourced from articles and research results published online in various sources such as Google Scholar, Scopus, and other scientific subjects. Some keywords used include Mirystica fragran, numteg, bioctivity of MF. The information obtained was synthesized so as to explain botany, the use of MF and its bioativity.

\section{RESULT AND DISCUSSIONS}

\subsection{Botany}

Myristica fragrans is a tree-lined plant with a height of $10 \mathrm{~m}$. All parts of the plant (roots, stems, leaves, 
flowers, fruits and seeds) have a distinctive aroma and are also known as aromatic plants. Most MF plants are two-seeded plants (dioceus), but are sometimes found to have a single house (monoeceus) (Sharma and Armstrong 2015; Silalahi et al 2019). Branching that emerges from the main stem is dense so that it looks lush. The old bark is dark in color. The location of the leaves is scattered in the form of a single leaf and, in the shape of obovatus or oval, with a size of $6-13 \times$ $3.5-6.5 \mathrm{~cm}$. The tip is tapered while the base of the leaf is pointed. The bottom side is paler (Silalahi et al 2019) (Figure 1).

Inflorescence arises between leaves right in the armpit or slightly supra axillar. Male inflorescences: slender stems with a length of 5-20 mm, flowers up to 5 per inflorescence, sometimes reduced to inflorescences with 1-3 flowers with long stems. Female inflorescences are generally shorter than male inflorescences, up to $5 \mathrm{~mm}$ thick, and each inflorescence is usually arranged up to 3 flower buds. Male flowers with long oval buds, 7-8 $\times 4-5 \mathrm{~mm}$, stamens converge, while female flowers are usually larger than male flowers, 7-8 $\times 5 \mathrm{~mm}$. Fruits are usually solitary, pear-shaped or almost rounded, when fresh between $6-9 \mathrm{~cm}$ with brown outer skin. Salut seeds are red and are divided into many segments close to the base. Jorong-shaped seeds widened to about $3 \mathrm{~cm}$ in length (Silalahi et al 2019). Pollination of MF mainly by beetles, thrips and flies (Sharma and Armstrong 2015). The single locus matK gene (maturase K) cannot be used to distinguish species in Myristica and can only be used to distinguish genus levels in the Myristicaceae family (Tallei and Kolondam 2015).

\subsection{Uses}

Myristica fragrans has been used by humans for thousands of years. Maluku Islands are thought to be the origin of MF so that it became one of the Dutch and Portuguese colonial destinations. Utilization of MF as a spice and also as medicine makes it a commodity with a very high economic value. The distinctive aroma produced by MF fruit makes it as a processed food that functions as a main ingredient and as an additional ingredient.

Although there are many benefits of MF, further studies are focused on its function in the health sector. The use of MF as a drug has been recorded in various traditional medical manuscripts such as Unani and Ayurveda. Tajuddin et al (2013) stated that MF was used as a sexual refresher for the Unani Medical System in India. Jaiswal et al (2009) stated that MF has activity as hypolipidemic and hypocholesterolemia, antimicrobial, antidepressant, aphrodisiac, improving memory, antioxidants and hepatoprotective properties. MF also has an anti-colitis function (Kim et al 2013). The bioactivity of the MF will be discussed further.
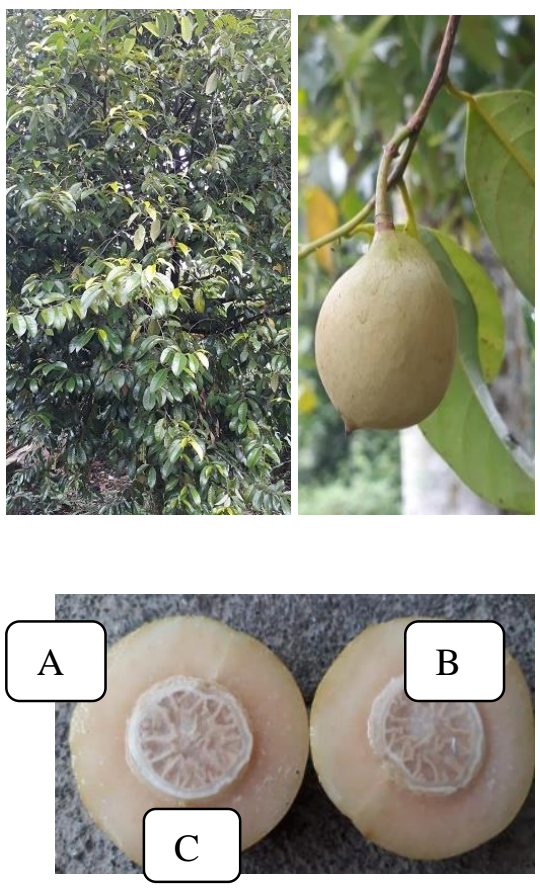

Figure 1. Nutmeg (Myristica fragrans Houtt). Top left. Habit; Top right. Young fruit; Below: cross section of young fruit.

\subsubsection{Antimicrobial}

Research on the use of MF as an anti-microbial is more prominent compared to other bioactivity. Antimicrobial compounds are compounds that can inhibit the growth of microbes. The bioactivity of MF as an anti-microbial can be used as a natural preservative of food, therefore the addition of MF in akam food has a dual effect of increasing flavor as well as preservatives. The ability of MF as an anti-microbial is thought to be related to its essential oil content (Rahmana et al 2011).

MF has anti-micro activity against Listeria monocytogenes (Rahmana et al 2011), Gram-positive bacteria (Streptococcus mutans, Streptococ-cus mitis, Streptococcus salivarius) and Gram-negative bacteria (Aggregatibacter actinomycetem-comitans, Porphyromonas gingivalis, Fusobacte-riumus aum). Bacterial activity can cause oral health problems Streptococcus mutans, Streptococcus mitis, Streptococcus salivarius, Aggregatibacter actinomycetemcomitans, Porphyromonas gingivalis, and Fusobacterium nucleatum, therefore the use of MF 
extract can be used as an agent in oral health care (Shafiei et al 2012).

The antibacterial activity of MF extracts is strongly influenced by various factors including concentration, extransients and materials extracted or used (Shafiei et aal 2012) and $\mathrm{pH}$ (Rahmana et al 2011). Among all the extracts tested, ethyl acetate extract from MF meat had the highest significant inhibitory effect on Grampositive bacteria (Streptococcus mutans, Streptococcus mitis, Streptococcus salivarius) and Gram negative bacteria (Aggregatibacter actinomycetemcomitans, Porphyromonas gingivalis, Stuspococcus nucleum with mean values). MIC values ranged from 0.625 to 1.25 $\mathrm{mg} / \mathrm{mL}$ and the highest bactericidal effect on the average $\mathrm{MBC}$ values ranging from $0.625 \mathrm{mg} / \mathrm{mL}$ to 20 $\mathrm{mg} / \mathrm{mL}$ (Shafiei et aal 2012).

Another factor that also affects MF activity is $\mathrm{pH}$. Rahmana et al (2011) states by decreasing the $\mathrm{pH}$ of the anti-bacterial effect of MF increasing. The acetone MF extract showed the strongest antibacterial and antifungal activity of Staphylococcus aureus (13.8 \pm $0.42 \mathrm{~mm})$ and Aspergillus niger (14.4 $\pm 0.37 \mathrm{~mm})$ respectively (Gupta et al 2013). GC-MS analysis of MF acetone extract has revealed the presence of 32 extract compounds representing $99.49 \%$. Sabinene (28.61\%) has shown the highest incidence in extracts. b-Pinene (10.26), a-pinene (9.72), myristicin (4.30\%), isoeugenol $(2.72 \%)$, p-cymene $(1.81 \%)$, carvacrol $(1.54 \%)$, eugenol $(0.89 \%)$ and b-caryophellene $(0.82 \%)$ were reported as possible contributors to MF antimicrobial activity (Gupta et al 2013).

Raw methanol extract of MF seeds contains 3', 4', 7-trihydroxyflavone. Coarse extract of MF seeds showed anti-bacterial activity with a minimum inhibitory concentration (MIC) ranging from 32 to $1024 \mu \mathrm{g} / \mathrm{mL}$ in most of the 29 tested by gram-negative bacterial strains. The lowest MIC value $(4 \mu \mathrm{g} / \mathrm{mL})$ was recorded with 3 ', 4', 7-trihydroxyfla-vone against Providenci astuartii ATCC 299645 and the best Bactericidal Concentration (MBC) value $(16 \mu \mathrm{g} / \mathrm{mL})$ for the same strain. The use of MF and the main antibacterial component, 3 ', 4 ', 7-trihydroxy-flavone, as a potential drug in the treatment of bacterial infections including phenotypes that are resistant to several drugs (Dzotam et al 2018).

\subsubsection{Anticolictis}

Colitis is a digestive disorder that causes inflammation in the rough intestine and rectum. MF water extract can protect colitis induced mice against sodium sulfate dextran (DSS) by inhibiting inflammatory cytokines (Kim et al 2013). Colitis is induced by $5 \%$ DSS in balb / c mice. MF extract (100,
300 or $1000 \mathrm{mg} / \mathrm{kg}$ ) orally administered to mice twice daily for 7 days can inhibit shortening of the large intestine and histological damage to the large intestine but does not prevent weight loss. MF water extract also inhibits proinflammatory cytokines (Kim et al 2013).

\subsubsection{APROSIDIAC}

Spices are considered as aphrodisiacs in the Unani Medical System (Tajuddin et al 2013). Administration of $50 \%$ ethanol extract of $\mathrm{MF}$ and Syzygium aromaticum (cloves) of $500 \mathrm{mg} / \mathrm{kg}$; p.o.) for 7 consecutive days increased the function of mating activity in male Swiss rats. Extracts (50\% ethanol) MF and cloves given $(500 \mathrm{mg} / \mathrm{kg}$; $\mathrm{p}$. The sexual activity of normal male rats without side effects is very significant with the administration of ethanol extract MF. Bioactivity of MF as an aphrodisiac and increase libido is associated with MF's ability to stimulate the nervous system (Tajuddin et al 2005).

\subsubsection{Antidepressan}

Depression is a psychiatric disorder that results in feelings of sadness and loss of interest and feeling depressed for a long time. Various types of plants including MF (Moinuddin et al 2012) have long been used to reduce depression, one of which is by using aromatherapy which is thought to cause a relaxing effect. MF and imipramine administration revealed a statistically significant decrease in immobility in the Forced Swimming Test (FST), Reserpine Reversal Test (RRT), and protection against Haloperidol-Induced Catalepsy (HIC), compared to the control group, however, there was no potentiation of Pentobarbitone Sleeping Significant time (Moinuddin et al 2012).

\subsubsection{Anticancer}

Cancer is one of the main causes of human death. In general, cancer is caused by uncontrolled cell growth. Sharing of factors is thought to cause cancer such as gene mutations and environmental factors. Lately research on plants that have the potential to be anti-cancer has greatly increased including MF. Potential anti-cancer plants are plants that can damage cancer cells, but not normal cells. Piaru et al (2011) stated that the MTT test of MF oil in human colorectal carcinoma (HCT-116) and human breast carcinoma cell lines (MCF-7) showed IC50 values of 78.61 and 66.45 $\mu \mathrm{gmL}-1$ respectively. He further stated that the anticancer activity in MF was related to essential oil. MF has anti-cancer activity as many as thirty-eight compounds found in MF oil were identified by gas 
chromatography-mass spectrometry (Piaru et al 2011). Four lignans, meso-dihydroguaiaretic acid (DHGA), macelignan, fragransin $\mathrm{A} 2$ and nectandrin $\mathrm{B}$, were isolated from nutmeg (Vietnam) MF seeds and had cytotoxic activity against eight cancer cell lines. DHGA showed strong cytotoxicity against H358 with an IC50 value of $10.1 \mathrm{lM}$. In addition, DHGA shows antitumor activity in mouse models containing allogenic tumors (Thuong et al 2011).

\subsubsection{Analgesic}

Analgesics are compounds that can reduce pain or tenderness. Visceral pain in the laboratory can be induced by acetic acid (Hayfaa et al 2013). Alkaloids from MF seeds have analgesic effects. To extract alkaloids from MF seeds, acetic acid and ethyl alcohol can be used. Visceral pain induced in male and female BALB / c mice by intraperitoneal injection of acetic acid $0.6 \%$, then given an alkaloid MF (0.5 gram or 1 gram per kilogram by mouth) significantly reduced the stretching response. Alkaloid extract at a dose of $1 \mathrm{~g} /$ $\mathrm{kg}$ significantly reduces the amount of writhing response in female rats, but not in male rats; $0.5 \mathrm{~g} / \mathrm{kg}$ of alkaloid extract has no effect on both sexes (Hayfaa et al 2013).

\section{CONCLUSIONS}

In ethnobotany, numteg is used as a cholesterol, prodisiac, hepatoprotective drug. Numteg's bioactivity functions as an antimicrobial, aphrosidiac, antidepressant, analgesic, anti-cancer, and anticolytic agent. The use of numteg as aprosidiak needs to be studied further so as to improve its function as a standardized or phytochemical herbal.

\section{REFERENCES}

1. Dzotam, J.K., Simo, I.K., Bitchagno, G., Celik, I., Sandjo, L.P., Tane, P., Kuete, V., 2018. In vitro antibacterial and antibiotic modifying activity of crude extract, fractions and $3^{\prime}, 4^{\prime}, 7$ trihydroxyflavone from Myristica fragrans Houtt against MDR Gram-negative enteric bacteria. BMC Complementary and Alternative Medicine 18:15. DOI 10.1186/s12906-018-2084-1 hal 1-9

2. Gupta, A.D., Bansal, V.K., Babu, V., Maithil, N., 2013. Chemistry, antioxidant and antimicrobial potential of nutmeg (Myristica fragrans Houtt). Journal of Genetic Engineering and Biotechnology 11: $25-31$.
3. Hayfaa, A.A.S., Al-Saadi Sahar, A.A.M. AlSaeidy Awatif, M., 2013. Evaluation of analgesic activity and toxicity of alkaloids in Myristica fragrans seeds in mice. Journal of Pain Research 6: 611-615.

4. Jaiswal, P., Kumar, P., Singh, V.K., Singh, D.K., 2009. Biological effects of Myristica fragrans. Annu Rev Biomed Sci. 11: 21-29.

5. Kim, H., Bu, Y., Lee, B.J., Bae, J., Park, S., Kim, J., Lee, K., Cha, J.M., Ryu, B., Ko, S.J., Han, G., Min, B., Park, J.W.,. 2013. Myristica fragrans seed extract protects against dextran sulfate sodiuminduced colitis in mice. Journal of Medicinal Food 10: 953-956.

6. Moinuddin, G., Devi, K., Khajuria, D.K., 2012. Evaluation of the anti-depressant activity of Myristica fragrans (Nutmeg) in male rats. Avicenna Journal of Phytomedicine 2(2): 72-78.

7. Piaru, S.P., Mahmud, R., Majid, A.M.S.A., Ismail, S., Manc, C.N. 2012. Chemical composition, antioxidant and cytotoxicity activities of the essential oils of Myristica fragrans and Morinda citrifolia. J Sci Food A gric 92: 593-597.

8. Rahnama, M., Najimi, M., Ali, S., 2011. Antibacterial effects of Myristica fragrans, Zataria multiflora Boiss, Syzygium aromaticum, and Zingiber officinale Rosci essential oils, alone and in combination with nisin on Listeria monocytogenes. Comp Clin Pathol. DOI 10.1007/s00580-011-1287-3: 1-4

9. Shafiei, Z., Shuhairi, N.N., Yap, N.M.F.S., Sibungkil, C.A.H., Latip, J., 2012. Antibacterial activity of Myristica fragrans against oral pathogens. Evidence-Based Complementary and Alternative Medicine Volume 2012, Article ID 825362, 7 pages. doi:10.1155/2012/825362.

10. Sharma, M.V., Armstrong, J.E. 2013. Pollination of Myristica and other nutmegs in natural populations. Journal - Tropical Conservation Science - Special Issue Vol.6 (5): 595-607.

11. Silalahi, M., Purba, E.C., Mustaqim, W., 2019. Tumbuhan obat Sumatera Utara Jilid II. Dikotilodenae, UKI Pres, Jakarta.

12. Tajuddin, Ahmad, S., Latif, A., Qasmi, I.A., 2003. Aphrodisiac activity of $50 \%$ ethanolic extracts of Myristica fragrans Houtt. (nutmeg) and Syzygium aromaticum (L) Merr. \& Perry. (clove) in male mice: a comparative study. BMC Complementary and Alternative Medicine 3(6): 1-5.

13. Tajuddin, Ahmad, S., Latif, A., Qasmi, I.A., Amin, K.M.Y., 2005. An experimental study of sexual function improving effect of Myristica fragrans Houtt. (nutmeg). BMC Complementary and 
Alternative Medicine 2005, 5:16 : 1-7. doi:10.1186/1472- 6882-5-16

14. Tallei, T.E., Kolondam, B.J.. 2015. DNA barcoding of sangihe nutmeg (Myristica fragrans) using matK Gene. Hayati Journal of Biosciences. 22(1): 41-47.
15. Thuong, P.T., Hung, T.M., Khoi, N.M., Nhung, NT Chinh, H.T.M., Quy, N.T., Jang, T.S., Na, M.K., 2014. Cytotoxic and anti-tumor activities of lignans from the seeds of Vietnamese nutmeg Myristica fragrans. Arch. Pharm. Res. 37: 399403. DOI 10.1007/s12272-013-0185-4. 